\section{Management of pruritus ani}

- Identify and treat secondary causes

- Give advice about personal hygiene

- Maintain the patient's confidence

- Avoid frequent unproductive clinic visits
Patients tend to make repeated visits to outpatient clinics with little improvement, seeing a different doctor at each visit. There is a danger that they will become disillusioned. An honest approach is best, warning the patient that a precise cause for their condition may not be found but that by paying attention to personal hygiene their symptoms can be minimised. In chronic cases a dermatological opinion is valuable to be sure that a skin condition such as psoriasis is not being missed.

The photographs were prepared by the department of medical illustration, Salford Health Authority.

Mr D J Jones is lecturer and honorary registrar in general surgery, Hope Hospital, Salford. The ABC of Colorectal Diseases has been edited by Mr D J Jones and Professor M H Irving, Hope Hospital, Salford.
Information Unit for the Conference of Joint Medical Royal Colleges and their Faculties in the UK, Department of Public Health Medicine, St Thomas's Hospital, London SE1 7EH Catherine Pope, research associate

BMF 1992;305:577-9

\title{
Cutting queues or cutting corners: waiting lists and the 1990 NHS reforms
}

\author{
Catherine Pope
}

According to the NHS Management Executive, ${ }^{1}$ from 1 April 1992 long waiting times for admission to hospital would be a thing of the past. Not only would the backlog of patients who had waited for more than two years have been cleared but the right of future patients to be admitted for treatment within two years would henceforth be guaranteed by the patient's charter. ${ }^{2}$ This promise was greeted with a certain amount of derision from government opposition parties in the general election campaign and there was, as it turned out, justified scepticism about the likelihood of success in meeting such targets. ${ }^{3}$

The patient's charter is a product of the current view that something must be done about long waiting times. The waiting list problem, which for so long has plagued the NHS, has been recast as "the problem of long waiting times." But waiting times are just one element of the waiting list problem. The length of time people wait to be admitted is undoubtedly important, but factors like severity, urgency, and the social and physical circumstances of the person waiting may be equally important in assessing the situation. ${ }^{4}$ The insistence on admitting those waiting for more than two years may be at the expense of more recent referrals of patients who are in greater need of treatment. A major flaw in the current rhetoric surrounding waiting lists and the furore about long waiting times is that it shows little understanding of what the waiting list problem really is. The charter, in common with other policies directed at waiting lists, seems to have been developed in a vacuum, without reference to existing research or explanations of waiting lists.

\section{The gap between research and policy}

Perhaps one of the clearest examples of the gap between research and policy is the way in which the 1990 NHS reforms tackle waiting lists. One of the central planks of government policy in the NHS and Community Care Act 1990 was the creation of 100 additional consultant posts to combat the waiting list problem, reduce junior doctors' hours, and improve the career structure. This policy was instigated despite a substantial body of research which suggested that waiting lists rise in tandem with any increase in consultant numbers ${ }^{5-7}$ and evidence that general practitioner referral rates are directly linked to the number of consultants available. ${ }^{8}$ Given that it is junior doctors who actually perform much of the routine surgery that makes up waiting lists, the combined impact of the reforms and the earlier recommendations of Achieving a Balance ${ }^{9}$ will mean fewer doctors to undertake waiting list work. Thus, extra consultant posts may actually increase the numbers of patients waiting and could lengthen average waiting times.

If the relationship, as some suggest, is one of "supplier induced demand" it would seem pertinent to investigate the links between demand for elective surgery and the numbers of doctors available before increasing the supply of doctors.

\section{Cutting corners}

Whatever the impact on waiting lists, the announcement of additional consultant posts fulfils a political

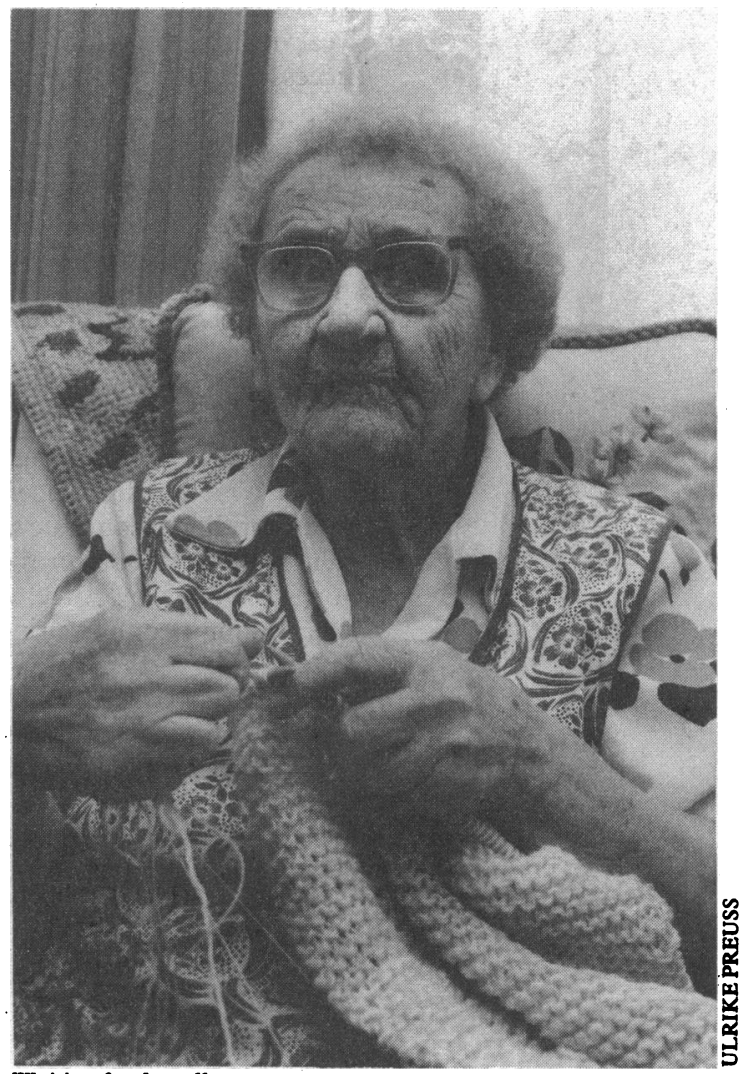

Waiting for the call 
desire to be seen to be doing something about the waiting list problem. This desire becomes all the more acute in the run up to a general election, when waiting lists become something of a political football. Anxious to celebrate the successes of the 1990 NHS reforms, the NHS Management Executive have been quick to attribute the $35 \%$ drop in numbers of people waiting more than two years to current government policy. They point to the significant increase in hospital activity as proof of a positive transformation in the NHS.

\section{Keeping the numbers down}

Yet the assertion that the reduction in numbers of people waiting over two years for inpatient treatment is linked to increased or more efficient hospital activity may well be fallacious. Cutting numbers can be achieved without actually treating patients. One way of doing this, pioneered by North East Thames Regional Health Authority, is simply to abolish certain embarrassing waiting lists altogether, such as those for varicose vein surgery. Another is to make inpatient waiting less visible, perhaps by making patients wait longer for outpatient appointments, temporarily suspending their admission, or sending them back to their general practitioner.

Even without such massaging it is often difficult to build up an accurate picture of waiting lists. Official waiting list statistics are often misleading or inaccessible. The cessation of the hospital inpatient enquiry in 1985 means that information on the waiting times of people admitted is no longer directly available. Information on those yet to be admitted is even more elusive.

Indeed, until 1984 the only national figures were those that the Department of Health deposited in the House of Commons library, after which they were deemed "published." In practice few people knew of or could make use of these figures.

In an effort to rectify this situation the College of Health, a national charity set up to provide NHS users with information about the health service, collected the statistics and published a Guide to Waiting Lists each year from 1984 to $1991 .^{10}$ This was one of the few accessible sources of information on waiting lists, and also included categories of patients, such as day cases, which the official statistics omit. After the implementation of the NHS and Community Care Act the College of Health stopped publishing the guide and, with a grant from the Department of Health, set up a waiting list information telephone line to help general practitioners refer patients.

Despite the success of this endeavour the Department of Health declined to extend the funding for the line and the college has had to secure interim funding from elsewhere. The long term future of this information service remains uncertain. Meanwhile the college is attempting to continue collecting waiting list figures. The last available figures from the College of Health, for September 1991, showed that there were still over one million people waiting for admission to hospital. Interestingly, the NHS Management Executive's report The First Six Months avoids mentioning this figure; it provides "provisional fast track" totals and statistics relating only to those who have waited over a year.

Such selective use of statistics is not confined to the NHS Management Executive, or to government ministers - as Yates has pointed out, opposition parties may have an equally biased perspective. ${ }^{11}$ One of the problems with the current political debate about waiting lists is that it does not encourage accurate statistical reporting from either side of the political divide. Nor does it engender long term planning and policy development; instead it seems to favour instant solutions, which almost inevitably cut corners.

The 1990 NHS reforms and the promises of the patient's charter are but the latest examples of a piecemeal approach to waiting list policy. They were preceded by the Department of Health's Waiting List Initiative Fund, which set aside annual funds of about $£ 30$ million to enable health authorities to tackle problem waiting lists in their districts. This funding, little more than the revenue of a small district health authority, meant that most of the projects set up under this initiative were small scale, consisting of blitzes on specific lists.

The initiative paid for extra theatre sessions to undertake knee replacements, or private hospital beds to admit patients who had waited over a year, or the use of military hospital facilities to treat patients on waiting lists, or extra day surgery. What these projects had in common was short term objectives - to get rid of a specific list or part of it - and not all were successful in achieving their aims.

The failure to make substantial progress with the waiting list problem has persisted despite several reports, notably the Duthie report, ${ }^{12}$ which actually identified the factors that generate long waiting times. Interestingly, some of the most successful work funded by the waiting list initiative was undertaken by John Yates and the Inter-Authority Comparisons and Consultancy. This group investigated 22 of the worst waiting lists in 43 specialties and identified some of the management and administrative causes of long waiting lists, such as inflation of lists with patients who had died or been treated.

The project achieved a significant reduction in the lists of all but four of the districts involved, yet this work was discontinued owing to a perceived lack of commitment by the government. ${ }^{13}$ This is especially disheartening as the consultancy's approach was one of the few attempts to understand the mechanisms that create and sustain waiting lists.

\section{Models of waiting lists}

The failure to understand waiting lists stems in part from the limitations of some of the theoretical models we use to describe them. The various policy initiatives described above assume that waiting lists are like bus queues. The emphasis of policy has therefore been on finding out why the queue doesn't move rather than explaining how it occurred. The patient's charter is just such an approach: it has merely shifted the focus to those at the end of the queue. But waiting lists are far more complex and dynamic than such queuing models suggest, and to understand them we need to get behind the queue and see what lists are and, crucially, how they are made.

Waiting lists vary enormously between hospitals and specialties: individual clinicians within the same hospital specialty may have vastly different lists in terms of case mix composition and waiting times. ${ }^{14}$ Most of the work waiting to be done is surgical, and the lists are dominated by a few distinct procedures such as hernia repair, varicose vein surgery, and knee or hip replacement. It seems less than coincidental that these are the very conditions which the private health care sector has chosen to focus on. ${ }^{15}$ Reports on variation in common surgical procedures provide further pointers to why such patterning occurs in waiting lists by indicating the way surgical preferences or "signatures" can shape the work surgeons do. ${ }^{16}$ Similar signatures seem to govern waiting lists.

Frankel has suggested that waiting lists resemble a "mortlake" or pool of work which is neglected because it contains conditions that neither the medical profession nor the general public are interested in. ${ }^{17}$ This idea 
has considerable salience, particularly when Frankel points to the paucity of publications in medical journals about waiting list conditions relative to the volume of work these conditions represent. In the new look NHS, pressure from purchasers and from within trust hospitals or directly managed units could be directed at altering these signatures, but as yet there is little evidence that major changes in consultants' contracts or surgical case mix have occurred.

The profile of surgical work may be influenced by other factors. In the absence of a price mechanism in the British health care system a waiting list signifies the demand for, and therefore the worth of, the doctor's services; in effect waiting lists denote desirability and prestige. Furthermore a waiting list, precisely because it is a pool of cases, may be a useful way of organising surgical work by allowing the selection of an appropriate mix of cases for theatre sessions and teaching junior staff.

These ideas provide some insight into how and why waiting lists may be produced. Other work suggests that the way waiting lists are organised may explain how they are sustained. One recent study has clearly shown that waiting lists are not administered as queues. ${ }^{18}$

This research showed that patients are not admitted in strict chronological order: differences in patient characteristics (both expected, like differences in urgency or severity, and unexpected, such as having a phone, which allows contact at short notice) determine how long individual patients wait. Even the way information about patients is stored can affect this process - for example, the use of paper based record systems, which provide instant, tactile, and visual representation of patients, lead to a quite different selection procedure than a first come first served queue.

In addition, different organisational practices such as theatre usage or bed management influence waiting lists. These aspects of waiting lists need to be examined to inform policy development. Unless we begin to understand how waiting lists work policy will remain little more than an exercise in playing with numbers, and there is a real danger that in our efforts to cut waiting we may cut corners, sweeping the true problem under the carpet.

I thank Professor W W Holland, Dr David Wild, Dr J A Roberts, and the anonymous referee for their comments on this paper.

The Information Unit is funded by the Nuffield Provincial Hospitals Trust.

1 NHS Management Executive. NHS reforms: the first six months. London: HMSO, 1990.

2 Department of Health. The patient's charter. London: HMSO, 1991. (HPCl.)

3 Waiting lists go up and down. BM $1992 ; 304: 1385$.

4 Radical Statistics Group. NHS reforms. The first six months: proof of progress Radical Statistics Group. NHS reforms. The first six m
or a statistical smokescreen? BMF 1992;304:705-9.

or a statistical smokescreen? $B M \mathcal{F}$ 1992;304:705-9.
Frost CEB, Francis BJ. Clinical decision-making: a study of general surgery rost CEB, Francis BJ. Clinical decision-making:
within Trent RHA. Soc Sci Med 1979;13a:193-8.

6 Buttery R, Snaith A. Surgical provision waiting times and waiting lists. Health Trends 1980;12:57-62.

7 Buttery R, Snaith A. Waiting for surgery. BMF 1979;ii:403-4.

8 Roland M, Morris R. Are referrals by general practitioners influenced by the availability of consultants? BMF 1989;297:599-600.

9 UK Health Departments, Joint Consultants Committee, Chairmen of Regional Health Authorities. Hospital medical staffing: Achieving a balance. London HMSO, 1986.

10 College of Health. Guide to hospital waiting lists. London: College of Health, 1991.

11 Yates J. Lies, damned lies, and waiting lists. BMf 1991;303:802.

12 Working Party to the Secretary of State for Social Services. Orthopaedic services: waiting times for outpatient appointments and inpatient treatment. London: HMSO, 1985.

13 Government criticised over waiting lists. BMJ 1992;304:57

14 Amos D, Woodyard J. Waiting lists the bare bones. Health Services fournal 1989;99:788-9.

15 Maynard A. Private practice: answer or irrelevance? BMF 1984;288:1849-51. 15 Maynard A. Private practice: answer or irrelevance? $B M F$ 1984;288:1849-51.
16 Wennberg JE, Barnes BA, Zubkoff $M$. Professional uncertainty and the problem of supplier induced demand. Soc Sci Med 1982;16:811-24.

17 Frankel $S$. The natural history of waiting lists: some wider explanations for an unnecessary problem. Health Trends 1989;21:56-8.

18 Pope C. Trouble in store: some thoughts on the management of waiting lists. Sociology of Health and Illness 1991;13:194-212.

(Accepted 25 fune 1992)
United States contain high radon concentrations, and mitigation is planned, but primarily because of the radon that escapes from water into indoor air.

Long term exposure of attendants could be a cause for concern, but the concentration of radon in the water would have to be exceptional before the resulting airborne activity became important. Direct emanation of radon from rock and soil in underground treatment centres is a more likely danger. In broad terms, the potential harm from smoking a cigarette is equal to that from a chest $x$ ray examination. Breathing air containing $5000 \mathrm{~Bq}$ of radon per $\mathrm{m}^{3}$ for about an hour would be an equivalent risk and indicates the risks to workers and to the small number of people who (often unknowingly) live in highly contaminated houses. ${ }^{2}$ In the United States dwellings have been found to contain up to $100000 \mathrm{~Bq}$ of radon per $\mathrm{m}^{3}$, but epidemiological studies to confirm risk factors have not yet reported conclusively. ${ }^{3}$ - STEPHEN WOZNIAK, environmental consultant, Abbots Langley, Hertfordshire

1 Jelliffe AM, Stewart F. Radium vita emanator. BMF 1969;i:305-6. 2 Wozniak SJ. Handbook of radon: health, economic and building aspects. Abbots Langley: S J Wozniak, 1992.

3 Miles DPB. Lung cancer and radon. BMF 1992;305:181. 